\title{
Perioperative Stroke Risk in Nonvascular Surgery
}

\author{
Federica Macellari Maurizio Paciaroni Giancarlo Agnelli Valeria Caso \\ Stroke Unit and Division of Cardiovascular Medicine, University of Perugia, Perugia, Italy
}

\author{
Key Words \\ Perioperative stroke $\cdot$ General surgery $\cdot$ Risk factors • \\ Antithrombotic therapy
}

\begin{abstract}
Background: Perioperative stroke is an ischemic or hemorrhagic cerebrovascular accident that can arise intraoperatively or from 3 to 30 days after surgery. This relatively rare complication deserves attention because of its high mortality and serious disability, the latter of which can lead to prolonged hospital stay as well as disscharge to long-term care facilities. The aim of this article was to review the literature on perioperative stroke in general surgery, excluding carotid and cardiac surgeries because these have already been thoroughly investigated in previous papers. Methods: A search strategy was designed to identify all relevant studies on perioperative stroke in the English language. This search was restricted to papers published up to December 5, 2011. Studies were initially identified from the Medline/PubMed database, EMBASE and the Cochrane Database using the search terms 'surgery', 'perioperative stroke', 'risk factors', 'anticoagulation treatment' and 'antiplatelet treatment'. Results: The incidence of perioperative stroke among patients who undergo nonvascular surgery is reported to be about $0.08-0.7 \%$. This depends on the type and complexity of the surgical procedure along with patient risk factors. The reported perioperative mortality is $18-26 \%$. One of the main issues is the man-
\end{abstract}

agement of patients taking anticoagulant or antiplatelet drugs, as the risk of bleeding has to be counterbalanced with the risk of arterial thrombosis due to discontinuation. Additionally, the presence of symptomatic carotid stenosis should be taken into account in the risk evaluation. Conclusions: To date, current guidelines are incomplete regarding the management of patients with vascular disease undergoing nonvascular surgery. It is recommended to stop oral anticoagulation approximately 5 days before major surgery to adequately allow the INR to normalize, and at the same time subcutaneous low-molecular-weight heparin or intravenous unfractionated heparin should be started. Regarding new anticoagulants, dabigatran does not need to be withheld for minor procedures. Currently, there are no clear recommendations on the use of rivaroxaban and apixaban. Data concerning the management of patients undergoing antiplatelet therapy are lacking. To date, neurologists discourage the perioperative withdrawal of aspirin (acetylsalicylic acid, ASA) especially in patients in secondary prevention. The 'Antiplatelet Agents in the Perioperative Management of Patients Trial' is ongoing to assess the safety and determine the optimal use of ASA in the perioperative management of patients undergoing general and abdominal surgery. In the meantime an individualized, accurate, multidisciplinary (surgical, neurological, cardiological and anesthesiological) risk/benefit assessment remains the best basis for treatment decision.

Copyright $\odot 2012$ S. Karger AG, Basel

\section{KARGER}

Fax +4161306 1234 E-Mail karger@karger.ch www.karger.com (c) 2012 S. Karger AG, Basel $1015-9770 / 12 / 0343-0175 \$ 38.00 / 0$

Accessible online at: www.karger.com/ced
Federica Macellari

Stroke Unit and Division of Cardiovascular Medicine

University of Perugia, Santa Maria della Misericordia Hospital

Sant'Andrea delle Fratte, IT-06126 Perugia (Italy)

Tel. +39075 578 2765, E-Mail federica.doc@ hotmail.it 


\section{Introduction}

Perioperative stroke is an ischemic or hemorrhagic cerebrovascular accident that can arise intraoperatively or from 3 to 30 days after surgery [1]. It is a relatively rare complication of surgical interventions which deserves attention because of its high mortality and serious disability that can lead to both prolonged hospital stay as well as discharge to long-term care facilities [2, 3]. Furthermore, the real incidence is most likely underestimated as the neurological deficits may be mild, transient or misdiagnosed because sedatives and narcotics often hinder neurological assessment $[1,4]$.

The aim of this article was to review the literature on perioperative stroke in general surgery, excluding carotid and cardiac surgeries because these have already been thoroughly investigated in previous papers [2, 5-14].

\section{Materials and Methods}

A search strategy was designed to identify all relevant studies on perioperative stroke in the English language. This search was restricted to papers published up to December 5, 2011. Studies were initially identified from the Medline/PubMed database, EMBASE and the Cochrane Database using the search terms 'surgery', 'perioperative stroke', 'risk factors', 'anticoagulation treatment' and 'antiplatelet treatment'. One of the researchers (F.M.) read all of the abstracts in order to choose pertinent papers for this review. If any doubt was raised on the pertinence of an article, a second opinion was requested from another author (V.C.).

\section{Results}

Of the 3,352 papers found during the literature search only 57 ( 33 studies and 24 reviews) have been considered relevant for the purpose of this review.

\section{Incidence}

The incidence of perioperative stroke among patients who undergo noncardiovascular surgery is reported to be about $0.08-0.7 \%$ (0.3-0.4\% symptomatic) $[3,4,15,16]$. The incidence increases with age: $0.1-0.2 \%$ for age $<65$ years, $0.5 \%$ for age $65-74$ years and $1.0 \%$ for age $\geq 75$ years $[3,4,17]$. Perioperative mortality is remarkably high at $18-26 \%[3,4,15,16]$.

\section{Timing}

The postoperative period is generally defined as $3-30$ days after surgery, while most perioperative strokes are identified within the first days after surgery $[1,4-6]$.

\section{Type of Surgery}

The incidence of perioperative stroke depends on the type of the surgical procedure: $0.08-0.7 \%$ general surgery, $0.2-0.9 \%$ orthopedic surgery and $0.6-0.9 \%$ lung operations [3, 17-20]. Neck and head surgery have been associated with a high rate of perioperative stroke: $4.8 \%$ [21] (table 1). This high risk might be due to hyperextension and rotation leading to overstretching and compression of the neck's major arteries that trigger intimal dissection, thrombus formation and vascular occlusion $[1,21]$. Furthermore, this incidence is most likely underestimated as these patients typically have a tracheostomy in place; thus, communication is compromised and a neurological evaluation, especially in the presence of slight changes, is difficult to perform and the neurological deficit may easily be missed.

\section{Causes and Pathophysiology}

The main reported causes of perioperative ischemic stroke include cerebral atherothrombosis, lacunar stroke, cardioembolism due to atrial fibrillation (AF), dehydration, hypotension and perioperative systemic hypercoagulability $[1,4,7,22]$. Other less common causes have been reported to be air, fat or paradoxical embolism and arterial dissection of neck arteries [18] (table 1). Perioperative strokes are predominantly ischemic and embolic rather than hemorrhagic $[9,10,16]$. New-onset AF is the comorbid diagnosis in $27.6 \%$ of postoperative stroke cases [3], leading to cardioembolism or cerebral hypoperfusion in those cases that develop a rapid ventricular response. Another cardiac source of emboli are diseased valves that can be favorable places for a thrombus to flourish because of alterations in blood flow coupled with perioperative hypercoagulability, hemodynamic changes and anticoagulation withholding [3].

\section{Risk Factors}

Patient-related risk factors include the following: age $>70$, female sex, previous stroke or transient ischemic attack, history of hypertension, diabetes mellitus, renal insufficiency, dialysis, smoking, chronic obstructive pulmonary disease, peripheral vascular disease, cardiac disease (history of myocardial infarction within 6 months prior to surgery, AF, valvular cardiopathy), carotid stenosis, atherosclerosis of the ascending aorta and the discontinuation of antithrombotic therapy before surgery. Procedure-related factors include timing of surgery (urgent vs. elective), type and duration of procedure, type of anesthesia (general vs. regional), intraoperative complications such as arrhythmia or heart rate alterations [23], 
hyperglycemia, dehydration and blood loss [18] (table 1). Particular attention is needed for those patients who have had previous stroke because they are at higher risk for perioperative cerebrovascular accidents $[1,2,5-7,11,12$, 19-21, 24-26]. In fact, general surgery has a low stroke risk of about $0.2 \%$ [19], but it increases to $2.9 \%$ in patients with precedent stroke [24] and rises to $3.6 \%$ in patients with carotid stenosis and prior symptoms [27]. If neurological symptoms are related to a basilar or intracranial vertebral artery stenosis, the perioperative stroke risk has been reported to be $6.0 \%$ with prolonged intraoperative hypotension acting as a precipitating factor [28]. The relation between asymptomatic carotid stenosis of any grade and the incidence of perioperative stroke in general elective surgery has not yet been determined [29].

\section{Anticoagulation Therapy before Surgery}

The management of patients taking oral anticoagulant (OAC) therapy is challenging because the risk of a thromboembolic event needs to be counterbalanced with the risk of bleeding. In a review of 31 reports on the perioperative treatment of patients receiving $\mathrm{OAC}$, arterial thromboembolism and stroke rates were reported to be 1.6 and $0.4 \%$, respectively, for all patients and 0.6 and $0.3 \%$, respectively, for patients who had been taking warfarin therapy withheld without the administration of intravenous heparin or subcutaneous low-molecular-weight heparin (LMWH) [30]. On the other hand, an increase in major bleeding over the first 2 postoperative days has been reported to be approximately $2-4 \%$ for major surgery and $0-2 \%$ for invasive procedures [30]. Regarding new OAC agents, the risk of severe bleeding with dabigatran has been reported to be similar to that of patients using LMWH in orthopedic surgery, and the same as or lower than patients with well-controlled AF on warfarin (3.11 vs. 3.36\%, respectively) [31]. Despite the clinical indication, patients with AF are frequently not put back on anticoagulation after surgery.

\section{Antiplatelet Withdrawal before Surgery}

Due to the high incidence of cardiovascular disease, antiplatelets are widely prescribed to up to $25 \%$ of the elderly population under aspirin (acetylsalicylic acid, ASA) treatment [32]. Antiplatelet drugs are effective in preventing arterial thrombosis both in primary $[33,34]$ and secondary [35] prevention but their continuation could lead to bleeding in the operative setting. This risk depends on the type of therapy (one, two or more antiplatelet drugs), surgical procedure (hip arthroplasty, tonsillectomy and transurethral resection of the prostate tend to bleed more; neurosurgery, ophthalmology and otorhinolaryngology
Table 1. Main causes and risk factors for perioperative stroke

Causes $[1,4,7,18,22]$

Cerebral atherothrombosis

Atrial fibrillation

Lacunar stroke

Dehydratation

Hypotension

Perioperative systemic hypercoagulability

Paradoxical embolism

Arterial dissection

Risk factors with odds ratios $[3,4,17,18,23]$

Age $>70$

$23.6(9.6-58.1)[17]$

Previous stroke or transient ischemic attack

$2.18(1.75-2.72)[3]$

$7.1(4.6-11)[17]$

Diabetes mellitus

Renal insufficiency and dialysis

Chronic obstructive pulmonary disease

Peripheral vascular disease

Cardiac disease

$\mathrm{AF}$

$2.2(1.4-3.3)[17]$

$1.42(1.25-1.62)[3]$

$5.36(4.68-6.13)[3]$

$1.61(1.44-1.81)[3]$

$2.20(1.77-2.74)[3]$

$3.98(3.57-4.45)[3]$

$5.5(2.8-10.9)[17]$

Congestive heart failure

$3.71(3.26-4.22)[3]$

Valvular disease

Ischemic heart disease

$2.51(2.10-2.99)[3]$

$1.75(1.56-1.97)[3]$

$2.3(1.3-4.1)[17]$

Angina pectoris

$2.5(1.4-4.4)$

Other risk factors

Female sex

Hypertension

Smoking

Carotid stenosis

Atherosclerosis of the ascending aorta

Discontinuation of antithrombotic therapy before surgery

Timing of surgery (urgent vs. elective)

Type and duration of procedure

Type of anaesthesia (general vs. regional)

Intraoperative complications (arrhythmia or heart rate altera-

tions)

Hyperglycemia

Dehydration

Blood loss

Type of surgery $[3,17-21,26,57]$

General $(0.08-0.7 \%)[3,26]$

Orthopedic $(0.2-0.9 \%)[3,20]$

Lung $(0.6-0.9 \%)[3,17]$

Peripheral vascular $(0.3-3 \%)[18,20]$

Neck and head $\left(3.2^{\mathrm{a}}-4.8 \%\right)[21,57]$

For risk factors, values in parentheses are $95 \%$ confidence intervals; for type of surgery, percent incidence is given in parentheses; the incidence is expressed as a range using the minimum and the maximum values described in the literature.

a Neck dissection and simultaneous carotid endarterectomy. 
Table 2. Management of patients with vascular disease undergoing noncardiovascular surgery

\section{Antiplatelet therapy}

ASA (primary prevention): stop 5 days prior to surgery and resume $24 \mathrm{~h}$ after surgery [40]

ASA (secondary prevention): do not withdraw [40]

Clopidogrel: stop 5 days before surgery and resume $24 \mathrm{~h}$ after surgery [39]

ASA + clopidogrel: continue both antiplatelets in the perioperative period; if bleeding risk reduction is required:

stop clopidogrel 5 days prior to surgery and continue ASA

consider 'bridging therapy' with short-acting intravenous glycoprotein IIb/IIIa inhibitors [52, 53]; bridging therapy with heparin not suggested [40]

resume clopidogrel $24 \mathrm{~h}$ after surgery [40]

Anticoagulant therapy [40]

Stop vitamin K antagonists and start subcutaneous LMWH or intravenous UFH 5 days before surgery

Stop subcutaneous LMWH $12 \mathrm{~h}$ (twice-daily regimen) or $24 \mathrm{~h}$ (once-daily regimen) prior to surgery

If UFH is used, stop it $4-6 \mathrm{~h}$ prior to surgery

Resume vitamin K antagonists + LMWH/UFH 12-24 h after surgery until INR therapeutic range is achieved

Dabigatran:

do not stop for minor procedures

stop $24 \mathrm{~h}$ to 5 days prior to major surgery (depending on renal function)

resume $1-4 \mathrm{~h}$ after the operation

consider bridging therapy with heparin if there is a high thrombotic risk

Carotid revascularization (carotid endartectomy or carotid artery stenting)

Symptomatic carotid stenosis $\geq 70 \%$ [47]

do not permit even minimal bleeding) and the sensitivity of patients to antiplatelet agents [36]. Patients taking ASA have a 1.5 -fold higher risk of blood loss without any increase in bleeding-related surgical mortality or morbidity [37]. Thus, low-dose ASA increases bleeding only quantitatively and does not move the bleeding complications toward a higher risk quality [37]. In fact, for anatomical reasons, urological interventions and diagnostic procedures tend to have a high rate of bleeding. In addition, a randomized controlled study has reported that there was no difference in intraoperative hemorrhage, operation time and amount of tissue resected between patients taking ASA during transurethral resection of the prostate and those not taking ASA, even though there was a reported increase in postoperative blood loss of 51\% (284 vs. $144 \mathrm{ml}$ ) [38]. Regarding clopidogrel, only a limited number of case reports and a small clinical series of visceral and vascular surgery have been published. However, a recent study has reported that patients receiving clopidogrel 5 days before lung resection had similar mortality, postoperative length of stay, rate of perioperative transfusion, reoperation for bleeding, myocardial infarction and stroke compared to controls sharing the same risk factors for both thrombosis and increased blood loss [39]. Thus, withdrawing clopidogrel only 5 days instead of 7-10 days [40] before major surgery seems to be safe and allows for adequate hemostasis. Clopidogrel plus
ASA increases surgical bleeding and the rate of transfusion by $50 \%$ without increasing morbidity, mortality or surgical outcome [41]. Nevertheless, this type of bleeding is rarely life threatening and can be managed like any other type and even prevented by using less invasive or advanced surgical approaches [42].

The abrupt discontinuation of antiplatelet agents, in fact, is associated with a rebound phenomenon that accentuates the problem and makes the thrombus formation more probable [43]. The time interval between discontinuation and acute cerebral events has been reported to be $14.3 \pm 11.3$ days [37]. Despite the high thrombotic risk, of 287 English urologists, 62\% withdrew ASA prior to transurethral resection of the prostate without specifying any reason [44]. Additionally, an American survey of ophthalmologists found that $52 \%$ discontinued ASA prior to surgery, while a survey of gastroenterologists reported that $81 \%$ stopped ASA before colonoscopy, $79 \%$ before endoscopic retrograde cholangiopancreatography and $51 \%$ prior to upper endoscopy $[45,46]$.

\section{Conclusions}

Even if the incidence of perioperative stroke among patients who undergo noncardiovascular surgery is reported to be very low $(0.3-0.4 \%$ symptomatic) $[3,4,15$, 
16], it nonetheless remains a devastating disease with a high perioperative mortality $(18-26 \%)[3,4,15,16]$. Management guidelines for patients with vascular disease undergoing surgery are insufficient and, therefore, surgeons generally make these decisions independently. On the basis of the findings of this review, the authors make the following recommendations (table 2).

Regarding symptomatic stenosis $\geq 70 \%$, carotid revascularization by carotid endartectomy or carotid artery stenting before general surgery is the standard care [47], while there is no evidence to date to support a prophylactic revascularization in asymptomatic patients that would expose them to a 2-fold higher risk of periprocedural stroke and myocardial infarction without significantly reducing the risk of stroke [48-50]. However, of these latter patients, those having hemodynamically significant bilateral carotid stenosis may benefit from revascularization [18].

The guidelines of the American College of Chest Physicians (ACCP) recommend stopping OACs approximately 5 days before major surgery to adequately allow the INR to normalize and, at the same time, to start the 'bridging anticoagulation' with subcutaneous LMWH or intravenous unfractionated heparin (UFH) at different dosages (therapeutic or prophylactic) and different timings depending on the individual thrombotic risk of the patient [40]. Specifically, as far as bridging therapy is concerned, the last dose of LMWH must be given no less than $12 \mathrm{~h}$ before the operation with a twice-daily regimen, or $24 \mathrm{~h}$ before the operation with a once-daily regimen to avoid the persistence of anticoagulant effect during surgery [51]. If intravenous UFH has been used, it should be stopped 4-6 h prior to surgery. OACs must be resumed 12-24 $\mathrm{h}$ after surgery together with heparin, as warfarin takes a few days to reach its full effect [40]. Regarding new anticoagulants, dabigatran does not need to be withheld for minor procedures, whereas for major surgery it has to be discontinued $24 \mathrm{~h}$ to 5 days prior to surgery depending on the risk of bleeding and on the renal function of the patient. Dabigatran can be resumed $1-4 \mathrm{~h}$ after surgery if the wound is stable, otherwise the resumption must be delayed. If the patient has a high thrombotic risk a perioperative bridging therapy with heparin should be considered. Currently, there are no clear recommendations on the use of rivaroxaban and apixaban.

Data concerning the management of patients undergoing antiplatelet therapy are lacking. To date, the ACCP guidelines discourage the perioperative withdrawal of ASA, especially in patients in secondary prevention [40]. If the interruption is absolutely needed, resumption within $24 \mathrm{~h}$ after the procedure is suggested [40]. When clopidogrel withdrawal is required in order to reduce perioperative bleeding, bridging therapy, which includes short-acting intravenous glycoprotein IIb/IIIa inhibitors such as tirofiban or eptifibatide (until just before intervention in those patients with coronary stent recently implanted), can be administered $[52,53]$. The ACCP guidelines suggest against the routine use of bridging therapy with UFH or LMWH because the efficacy and safety data on patients taking antiplatelet therapy are lacking [40]. In fact, heparin does not have antiplatelet properties and is not protective against stent thrombosis [54, 55]. Despite this, many surgeons substitute antiplatelet therapy with LMWH as an antithrombotic bridging therapy or, empirically, use the same doses of the venous thromboembolism prophylaxis.

The Antiplatelet Agents in the Perioperative Management of Patients Trial, an ongoing randomized controlled trial, has the aim of assessing the safety and determining the optimal use of ASA in the perioperative management of patients undergoing general and abdominal surgery. This is being done by comparing a group of low-risk patients, who were withdrawn from ASA 5 days prior to surgery and resumed taking it 5 days after the intervention, to controls who did not discontinue the antiplatelet agent [56].

While waiting upon the results of the above-mentioned and other trials, an individualized, accurate, multidisciplinary (surgical, neurological, cardiological and anesthesiological) risk/benefit assessment remains the best basis for treatment decision.

\section{References}

Kim J, Gelb AW: Predicting perioperative stroke. J Neurosurg Anesthesiol 1995;7:211215.

-2 McKhann GM, Grega MA, Borowicz LM Jr, Baumgartner WA, Selnes OA: Stroke and encephalopathy after cardiac surgery: an update. Stroke 2006;37:562-571.

\footnotetext{
3 Bateman BT, Schumacher HC, Wang S, Shaefi S, Berman MF: Perioperative acute ischemic stroke in noncardiac and nonvascular surgery: incidence, risk factors, and outcomes. Anesthesiology 2009;110:231-238.

$\checkmark 4$ Kikura M, Bateman BT, Tanaka KA: Perioperative ischemic stroke in non-cardiovascular surgery patients. J Anesth 2010;24:733-738.
} 
$\checkmark 5$ Bucerius J, Gummert JF, Borger MA, Walther T, Doll N, Onnasch JF, Metz S, Falk V, Mohr FW: Stroke after cardiac surgery: a risk factor analysis of 16,184 consecutive adult patients. Ann Thorac Surg 2003;75:472-478.

$\checkmark 6$ Likosky DS, Marrin CA, Caplan LR, Baribeau YR, Morton JR, Weintraub RM, Hartman GS, Hernandez F Jr, Braff SP, Charlesworth DC, Malenka DJ, Ross CS, O'Connor GT: Determination of etiologic mechanisms of strokes secondary to coronary artery bypass graft surgery. Stroke 2003;34:28302834.

$\checkmark 7$ Likosky DS, Caplan LR, Weintraub RM, Hartman GS, Malenka DJ, Ross CS, Landis ES, Applebaum B, Braff SP, O'Connor GT: Intraoperative and postoperative variables associated with strokes following cardiac surgery. Heart Surg Forum 2004;7:E271E276.

8 Naylor AR, Mehta Z, Rothwell PM, Bell PR: Carotid artery disease and stroke during coronary artery bypass: a critical review of the literature. Eur J Vasc Endovasc Surg 2002;23:283-294.

-9 Restrepo L, Wityk RJ, Grega MA, Borowicz L Jr, Barker PB, Jacobs MA, Beauchamp NJ, Hillis AE, McKhann GM: Diffusion- and perfusion-weighted magnetic resonance imaging of the brain before and after coronary artery bypass grafting surgery. Stroke 2002; 33:2909-2915.

$>_{10}$ Brooker RF, Brown WR, Moody DM, Hammon JW Jr, Reboussin DM, Deal DD, GhaziBirry HS, Stump DA: Cardiotomy suction: a major source of brain lipid emboli during cardiopulmonary bypass. Ann Thorac Surg 1998;65:1651-1655.

-11 Hogue CW Jr, Murphy SF, Schechtman KB, Davila-Roman VG: Risk factors for early or delayed stroke after cardiac surgery. Circulation 1999;100:642-647.

-12 van Wermeskerken GK, Lardenoye JW, Hill SE, Grocott HP, Phillips-Bute B, Smith PK, Reves JG, Newman MF: Intraoperative physiologic variables and outcome in cardiac surgery. Part II. Neurologic outcome. Ann Thorac Surg 2000;69:1077-1083.

$\checkmark 13$ Jongen LM, Hendrikse J, Moll FL, Mali WP, van der Worp HB: Cerebral perfusion affects the risk of ischemia during carotid artery stenting. Cerebrovasc Dis 2010;29:538-545.

14 Korn-Lubetzki I, Steiner I, Oren A, Tauber R, Steiner-Birmanns B, Bitran D: The possible risk for strokes complicating cardiac surgery in patients with intraoperative hypothermia. Cerebrovasc Dis 2010;30:602-605.

-15 Parikh S, Cohen JR: Perioperative stroke after general surgical procedures. NY State J Med 1993;93:162-165.

-16 Limburg M, Wijdicks EF, Li H: Ischemic stroke after surgical procedures: clinical features, neuroimaging, and risk factors. Neurology 1998;50:895-901.
17 Kikura M, Oikawa F, Yamamoto K, Iwamoto T, Tanaka KA, Sato S, Landesberg G: Myocardial infarction and cerebrovascular accident following non-cardiac surgery: differences in postoperative temporal distribution and risk factors. J Thromb Haemost 2008;6: 742-748.

18 Selim M: Perioperative stroke. N Engl J Med 2007;356:706-713.

19 Larsen SF, Zaric D, Boysen G: Postoperative cerebrovascular accidents in general surgery. Acta Anaesthesiol Scand 1988;32:698-701.

20 Wong GY, Warner DO, Schroeder DR, Offord KP, Warner MA, Maxson PM, Whisnant JP: Risk of surgery and anesthesia for ischemic stroke. Anesthesiology 2000;92: 425-432.

21 Nosan DK, Gomez CR, Maves MD: Perioperative stroke in patients undergoing head and neck surgery. Ann Otol Rhinol Laryngol 1993;102:717-723.

22 Blacker DJ, Flemming KD, Link MJ, Brown RD Jr: The preoperative cerebrovascular consultation: common cerebrovascular questions before general or cardiac surgery. Mayo Clin Proc 2004;79:223-229.

23 Mortazavi SM, Kakli H, Bican O, Moussouttas M, Parvizi J, Rothman RH: Perioperative stroke after total joint arthroplasty: prevalence, predictors, and outcome. J Bone Joint Surg Am 2010;92:2095-2101.

24 Landercasper J, Merz BJ, Cogbill TH, Strutt PJ, Cochrane RH, Olson RA, Hutter RD Perioperative stroke risk in 173 consecutive patients with a past history of stroke. Arch Surg 1990;125:986-989.

25 Knapp RB, Topkins MJ, Artusio JF Jr: The cerebrovascular accident and coronary occlusion in anesthesia. JAMA 1962;182:332334.

26 Kam PC, Calcroft RM: Peri-operative stroke in general surgical patients. Anaesthesia 1997;52:879-883.

27 Evans BA, Wijdicks EF: High-grade carotid stenosis detected before general surgery: is endarterectomy indicated? Neurology 2001; 57:1328-1330.

28 Blacker DJ, Flemming KD, Wijdicks EF: Risk of ischemic stroke in patients with symptomatic vertebrobasilar stenosis undergoing surgical procedures. Stroke 2003;34:2659-2663.

29 Paciaroni M, Caso V, Acciarresi M, Baumgartner RW, Agnelli G: Management of asymptomatic carotid stenosis in patients undergoing general and vascular surgical procedures. J Neurol Neurosurg Psychiatry 2005;76:1332-1336.

30 Dunn AS, Turpie AG: Perioperative manage ment of patients receiving oral anticoagulants: a systematic review. Arch Intern Med 2003;163:901-908.
31 Connolly SJ, Ezekowitz MD, Yusuf S, Eikelboom J, Oldgren J, Parekh A, Pogue J, Reilly PA, Themeles E, Varrone J, Wang S, Alings M, Xavier D, Zhu J, Diaz R, Lewis BS, Darius H, Diener HC, Joyner CD, Wallentin L: Dabigatran versus warfarin in patients with atrial fibrillation. N Engl J Med 2009;361: 1139-1151.

>32 Shahar E, Folsom AR, Romm FJ, Bisgard KM, Metcalf PA, Crum L, McGovern PG, Hutchinson RG, Heiss G: Patterns of aspirin use in middle-aged adults: the atherosclerosis risk in communities (ARIC) study. Am Heart J 1996;131:915-922.

33 Cannon CP: Elderly patients with acute coronary syndromes: higher risk and greater benefit from antiplatelet therapy and/or interventional therapies. Am J Geriatr Cardiol 2003; 12:259-262.

34 Dornbrook-Lavender KA, Pieper JA, Roth MT: Primary prevention of coronary heart disease in the elderly. Ann Pharmacother 2003;37:1654-1663.

35 Collaborative meta-analysis of randomised trials of antiplatelet therapy for prevention of death, myocardial infarction, and stroke in high risk patients. BMJ 2002;324:71-86

36 Lecompte T, Hardy JF: Antiplatelet agents and perioperative bleeding. Can J Anaesth 2006;53:S103-S112.

$>37$ Burger W, Chemnitius JM, Kneissl GD, Rucker G: Low-dose aspirin for secondary cardiovascular prevention - cardiovascular risks after its perioperative withdrawal versus bleeding risks with its continuation - review and meta-analysis. J Intern Med 2005; 257:399-414.

-38 Nielsen JD, Holm-Nielsen A, Jespersen J, Vinther CC, Settgast IW, Gram J: The effect of low-dose acetylsalicylic acid on bleeding after transurethral prostatectomy - a prospective, randomized, double-blind, placebo-controlled study. Scand J Urol Nephrol 2000;34:194-198.

39 Ceppa DP, Welsby IJ, Wang TY, Onaitis MW, Tong BC, Harpole DH, D’Amico TA, Berry MF: Perioperative management of patients on clopidogrel (Plavix) undergoing major lung resection. Ann Thorac Surg 2011;92: 1971-1976.

$\checkmark 40$ Douketis JD, Berger PB, Dunn AS, Jaffer AK, Spyropoulos AC, Becker RC, Ansell J: The perioperative management of antithrombotic therapy: American College of Chest Physicians Evidence-Based Clinical Practice Guidelines, ed 8. Chest 2008;133: 299S-339S.

-41 Di Minno MN, Prisco D, Ruocco AL, Mastronardi P, Massa S, Di Minno G: Perioperative handling of patients on antiplatelet therapy with need for surgery. Intern Emerg Med 2009;4:279-288. 
-42 Samama CM, Bastien O, Forestier F, Denninger $\mathrm{MH}$, Isetta $\mathrm{C}$, Juliard JM, Lasne $\mathrm{D}$, Leys D, Mismetti P: Antiplatelet agents in the perioperative period: expert recommendations of the French Society Of Anesthesiology And Intensive Care (SFAR) 2001 - summary statement. Can J Anaesth 2002;49:S26S35.

-43 Beving H, Zhao C, Albage A, Ivert T: Abnormally high platelet activity after discontinuation of acetylsalicylic acid treatment. Blood Coagul Fibrinolysis 1996;7:80-84.

44 Enver MK, Hoh I, Chinegwundoh FI: The management of aspirin in transurethral prostatectomy: current practice in the UK. Ann R Coll Surg Engl 2006;88:280-283.

-45 Kadakia SC, Angueira CE, Ward JA, Moore M: Gastrointestinal endoscopy in patients taking antiplatelet agents and anticoagulants: survey of ASGE members. American Society for Gastrointestinal Endoscopy. Gastrointest Endosc 1996;44:309-316.

46 Stone LS, Kline OR Jr, Sklar C: Intraocular lenses and anticoagulation and antiplatelet therapy. J Am Intraocul Implant Soc 1985;11: 165-168.

-47 Barnett HJ, Taylor DW, Eliasziw M, Fox AJ, Ferguson GG, Haynes RB, Rankin RN, Clagett GP, Hachinski VC, Sackett DL, Thorpe KE, Meldrum HE, Spence JD: Benefit of carotid endarterectomy in patients with symptomatic moderate or severe stenosis. North American Symptomatic Carotid Endarterectomy Trial Collaborators. N Engl J Med 1998;339:1415-1425.
48 Gerraty RP, Gates PC, Doyle JC: Carotid stenosis and perioperative stroke risk in symptomatic and asymptomatic patients undergoing vascular or coronary surgery. Stroke 1993;24:1115-1118.

49 Chaturvedi S, Bruno A, Feasby T, Holloway R, Benavente O, Cohen SN, Cote R, Hess D Saver J, Spence JD, Stern B, Wilterdink J: Carotid endarterectomy - an evidence-based review: report of the Therapeutics and Technology Assessment Subcommittee of the American Academy of Neurology. Neurology 2005;65:794-801.

50 Barnett HJ, Meldrum HE: Endarterectomy for carotid stenosis: new approaches in patient selection. Cerebrovasc Dis 2001;11(suppl 1):105-111.

51 Thachil J, Gatt A, Martlew V: Management of surgical patients receiving anticoagulation and antiplatelet agents. Br J Surg 2008; 95:1437-1448.

52 Savonitto S, D’Urbano M, Caracciolo M Barlocco F, Mariani G, Nichelatti M, Klugmann S, De Servi S: Urgent surgery in patients with a recently implanted coronary drug-eluting stent: A phase II study of 'bridging' antiplatelet therapy with tirofiban during temporary withdrawal of clopidogrel. $\mathrm{Br}$ J Anaesth 2010;104:285-291.
53 Savonitto S, Caracciolo M, Cattaneo M, De Servi S: Management of patients with recently implanted coronary stents on dual antiplatelet therapy who need to undergo major surgery. J Thromb Haemost 2011;9:21332142.

54 Collet JP, Montalescot G, Blanchet B, Tanguy ML, Golmard JL, Choussat R, Beygui F, Payot L, Vignolles N, Metzger JP, Thomas D: Impact of prior use or recent withdrawal of oral antiplatelet agents on acute coronary syndromes. Circulation 2004;110:2361-2367.

55 Batchelor WB, Mahaffey KW, Berger PB, Deutsch E, Meier S, Hasselblad V, Fry ET, Teirstein PS, Ross AM, Binanay CA, Zidar JP: A randomized, placebo-controlled trial of enoxaparin after high-risk coronary stenting: the ATLAST trial. J Am Coll Cardiol 2001;38:1608-1613.

56 Antolovic D, Reissfelder C, Rakow A, Contin P, Rahbari NN, Buchler MW, Weitz J, Koch $\mathrm{M}$ : A randomised controlled trial to evaluate and optimize the use of antiplatelet agents in the perioperative management in patients undergoing general and abdominal surgery - the APAP trial (ISRCTN45810007). BMC Surg 2011;11:7.

57 Rechtweg J, Wax MK, Shah R, Granke K, Jarmuz T: Neck dissection with simultaneous carotid endarterectomy. Laryngoscope 1998; 108:1150-1153. 